\title{
Impact of Stability Ball Sitting during Semi-recumbent Exercise*
}

\author{
Charles R.C. Marks", Steve Grapsas, Deborah Malushi \\ Human Movement Science, Exercise Science Program, School of Health Sciences, Oakland University, Rochester, MI, USA
}

Copyright $\bigcirc 2018$ by authors, all rights reserved. Authors agree that this article remains permanently open access under the terms of the Creative Commons Attribution License 4.0 International License

\begin{abstract}
Purpose: This study determined if sitting on a stability ball (B), when compared to sitting on a chair (C), affects cardiorespiratory and muscular recruitment during semi-recumbent exercise. Methods: Participants sat on B or $\mathrm{C}$ behind a cycle ergometer using the bike seat for hand griping. Open-circuit spirometry and HR were monitored continuously during graded exercise. Initial two stages of exercise also had hip movements and the right arm, trunk, and leg EMGs recorded. Eighteen apparently healthy adults exercised twice, one trial on $\mathrm{B}$ and the other trial on $\mathrm{C}$ (order randomized). ANOVA for repeated measures $(\alpha<$ $0.05)$ was used for statistical analysis. Results: Only at peak was $\mathrm{VO}_{2}$ significantly higher $(P=0.001)$ for $\mathrm{B}$ compared to $\mathrm{C}$. There was no significant $(P=0.291)$ difference between $\mathrm{B}$ and $\mathrm{C}$ for HR. Stage 2 hip movements were significantly $(P<0.001)$ higher while some leg EMGs were significantly $(P<0.019)$ lower on B compared to $\mathrm{C}$. In addition, flexor digitorum EMG was significantly $(P<0.036)$ higher on $\mathrm{B}$ compared to $\mathrm{C}$. Conclusion: The stability ball increases hip motion and may alter muscular recruitment pattern during semi-recumbent exercise with little impact on cardiorespiratory parameters.
\end{abstract}

Keywords Cardiovascular, Aerobic Leg Exercise, Swiss Ball, $\mathrm{VO}_{2}$

\section{Introduction}

While most studies investigating the use of a stability ball have focused on its potential to increase core muscle activity $[1,2,3]$ and as a replacement for chair sitting to possibly prevent or attenuate low back pain $[4,5]$, studies comparing chair sitting to stability ball sitting during sub-maximal \& maximal aerobic arm ergometry have also been reported $[6,7]$. These studies have demonstrated higher $\mathrm{VO}_{2} \mathrm{~s}[6,7]$ and partial core muscle activity [7]. This paucity of research indicates that some type of aerobic exercise with a stability ball is possible. However, aerobic arm exercise is limited in its physiological response to exercise when compared to leg exercise $[8,9]$ and fitness and rehabilitation centers encourage the use of both leg and arm aerobic exercise stations. If aerobic leg exercise could be done on a stability ball then another leg station with higher metabolic response and perhaps greater core muscle activity may be available.

Semi-recumbent exercise has been studied in healthy $[10$, 11], cardiac [12], and hypertensive [13] populations. However, semi-recumbent exercise equipment typically requires specialized equipment that can cost from $\$ 200$ to $\$ 3000$. Most clinical exercise and fitness centers have cycle ergometers, chairs, and stability balls. These can be used to create a semi-recumbent exercise station by placing a chair or stability ball behind the cycle ergometer. Since the stability ball appeared to elevate $\mathrm{VO}_{2}$ with little impact on heart rates when compared to chair sitting during arm ergometry [6,7], we might expect a higher $\mathrm{VO}_{2}$ with perhaps little impact on heart rates when comparing stability ball sitting to chair sitting during semi-recumbent exercise. Therefore, the purposes of this study were 1) to demonstrate if semi-recumbent exercise can be accomplished using a standard cycle ergometer, 2) determine if sitting on a stability ball (B) affects the cardiorespiratory responses to continuous graded semi-recumbent leg exercise to exhaustion when compared to sitting on a chair (C), and 3) determine if B affects muscle recruitment.

\section{Methods}

Female and male young adult participants were recruited after the University Institutional Review Board approval. Participants had to be 18 to 40 years of age, apparently healthy, and were at least moderately active (e.g. 3 days/week of walking 30 minutes/day).

Participants came to the laboratory on three separate days: one day for informed consent and orientation 
followed by two days of semi-recumbent graded exercise testing (SGXT). On the first day the participant practiced sitting on B while leg pedaling 60 to 80 revolutions per minute (rpm) in the semi-recumbent position. Blood pressure was also done to familiarize the participant to the procedure. To ensure that both condition's sitting heights were about the same, sitting right shoulder heights from the floor were measured using a stadiometer. A wooden platform was placed under the lower sitting mode to adjust the sitting height to be within two centimeters of each other. Body mass was also measured that day using a balance scale (Detecto, Webb, MO).

The subsequent two days of testing (24 hours apart) used a randomized cross over design where one day the participants sat on a chair during the SGXT while on the other day the participants sat on a stability ball during the SGXT. Prior to the SGXT the participants were prepped for heart rate, left arm blood pressure monitoring, electromyography (EMG), video capture, and open circuit spirometry. Two $\mathrm{Ag} / \mathrm{AgCl}$ surface $\mathrm{EMG}$ electrodes were placed over each muscle group following shaving, moderate sandpapering, and alcohol rubbing of the skin electrode area. The right side muscle groups and electrode placements were flexor digitorum-two centimeters apart on ventral side over area of greatest movement when fingers flexed; erector spinae-two centimeters apart on lower back parallel to and lateral two centimeters from the spine at the iliac crest level; external oblique-two centimeters apart halfway between the iliac crest and the anterolateral ribs on a slightly oblique angle superior to the anterior superior iliac spine; quadriceps-10 centimeters apart along upper leg's anterior midline with the midpoint of the electrode distance halfway between knee and iliac spine; hamstrings-three centimeters apart along the center of the posterior upper leg halfway between the gluteal fold and posterior knee; and general gastrocnemius-five centimeters apart with one on the lateral head and the other on the medial head. For the video capture, the left mid axillary line, lateral knee joint, lateral malleolus, and right and left greater trochanters had bright orange markers placed over them. For the SGXT the B and C were placed behind the cycle ergometer (see Picture 1). Participants repositioned B or $\mathrm{C}$ and themselves in ways that gave them a sense of being centered on $\mathrm{B}$ or $\mathrm{C}$ while pedaling. After four minutes of rest, the SGXT began at $60 \mathrm{~W}$ and increased by $30 \mathrm{~W}$ every two minutes until the participant could no longer maintain the rpm. Prior to changing the power output the participants presented their left arm to an investigator for the blood pressure measurement. The first few stages of exercise increased power output by increasing resistance while maintaining $60 \mathrm{rpm}$. However, an earlier pilot study (unpublished results) indicated that when resistance was about $30 \mathrm{~N}$ controlling the position of the stability ball became too difficult; therefore, increases in power output were made by changes in rpm in the later stages. A two-minute active recovery period followed termination of the SGXT. Following the recovery period of the second SGXT, each muscle group had a maximal voluntary contraction (MVC) EMG recorded and used for indexing the cycling EMG readings.

The $\mathrm{C}$ seat was $44 \mathrm{~cm}$ high (unless adjusted) and had no back or arm support. The B had a $75 \mathrm{~cm}$ diameter without anyone sitting on it. A cycle ergometer (Monark $818 \mathrm{E}$, Vansbro, Sweden) with a digital display for rpm that could be viewed by the participants was used for the SGXT. The cycle ergometer was modified by removing the back floor cross support (the heel of some large shoes could hit it during cycling). To help stabilize the ergometer during the maximal \& near maximal efforts suction cups were attached to the bracket that secured the back cross support and two $22 \mathrm{~kg}$ weights were placed on the front floor cross support (see Picture 1).

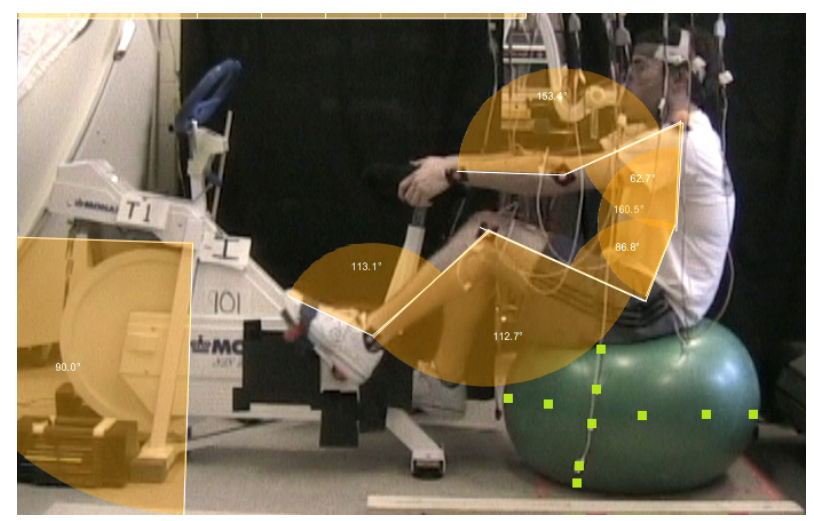

Picture 1. Semi-recumbent Exercise on a Stability Ball

$\mathrm{VO}_{2}$ was measured by open-circuit spirometry (TrueOne 2400, ParvoMedics, Sandy, UT) and calibrated before each exercise session. HR was recorded using a Polar monitor (Polar Electro Inc., Woodbury, NY) with the sensor connected to the TrueOne 2400 computer. Systolic (SBP) and Diastolic (DBP) blood pressures were measured using an aneroid sphygmomanometer and stethoscope. Videos were recorded by two camcorders (Sony, DCR-SX85) set four meters (back view) and six meters (left side view-see Picture 1) from participant. EMG signal band width was set at $10 \mathrm{~Hz}$ to $500 \mathrm{~Hz}$, the common mode rejection ratio was $110 \mathrm{~dB}$, the gain set at 5,000x, and sampling rate at 1000/sec using MP 100 system (BIOPAC, Santa Barbara, Calf.).,

$\mathrm{VO}_{2}$ and heart rate (HR) were monitored continuously during rest and the SGXT with the last 30 seconds of each stage used for analysis. To determine the level of muscle activity EMGs were recorded during the last 10 seconds of the first two stages of exercise. The EMG muscle activities were visually determined for three muscle contractions and the middle $2 / 3$ rds of the activities were highlighted for analysis. Root mean square for each muscle activity was determined using the MP 100 software and the average of the three contractions was calculated. The EMG values were then normalized to the maximal measurements. Our laboratory reliabilities (unpublished) for this EMG analysis 
is 0.98 (Intra-investigator) and 0.96 (Inter-investigator). Also during the last 10 seconds of the first two stages of exercise a video recorded the movements of the bright orange markers. The video capture was analyzed for right hip vertical (highest point to lowest point) and lateral (farthest to the right to farthest to the left) maximal displacement. In addition, the second stage of exercise was analyzed for left hip and knee angles at four crank positions $90^{\circ}$ apart: Vertical Superior, Horizontal Distal, Vertical Inferior, and Horizontal Proximal. Video analysis determined the success of maintaining the same seating position between $\mathrm{B}$ and $\mathrm{C}$ by assessing the sitting heights and body positions. Videos were analyzed using Connect 5.5 (Dartfish, Fribourg, Switzerland, see Picture 1). Blood pressure was measured only up to about $50 \%$ of peak because participants needed both arms to control their position during the higher power outputs. To supplement the EMGs for assessing muscular activity, the participant's perception of differences in muscular effort between B and $\mathrm{C}$ were assessed by asking them to verbally answer the following question after the second SGXT: "what did you feel was different between the stability ball and the chair for muscle activity?" The participants' answers were written down by an investigator.

Measurements at the $60 \mathrm{~W}, 50 \%$ of peak power output, Penultimate, and Peak stages were analyzed for $\mathrm{VO}_{2}$ and HR using an ANOVA mixed model: 2 (sitting mode) x 4 (Power Output) repeated measures with 2 (sex) between groups. $\mathrm{VO}_{2}$ analysis also used body mass as a covariate. SBP and DBP were analyzed at $60 \mathrm{~W}, 90 \mathrm{~W}$ and $50 \%$ of peak power output using an ANOVA mixed model: 2 (sitting mode) x 3 (Power Output) repeated measures with 2(sex) between groups. Measurements of EMG and hip movement were analyzed using 2 (sitting mode) 2 (power output) repeated measures ANOVA. Knee and Hip angles were analyzed by a 2 (sitting mode) x 4 (crank position) repeated measures ANOVA. ANOVAs had significance set at $\alpha<0.05$. If a significant main effect for sitting mode was found then paired $t$ tests with Holm's Sequential Bonferroni procedure [14] was used for follow-up analyses with an overall $\alpha<0.05$ (e.g. $0.0167,0.025, \& 0.05$ for a family of 3 contrasts). SPSS version 11.5 was used for all statistical analyses. The perceived differences between B and $\mathrm{C}$ were grouped into similar responses and expressed as percentage of total participants.

\section{Results}

After the first 16 participants completed the study two male participants were added to balance the number of males and females. One participant had his foot slip off the pedal near the peak stage of one test so the test was repeated five days later. Table 1 contains the participant characteristics. Each participant achieved the same peak power output for both sitting modes (Mean $\pm \mathrm{SD}=215 \pm$
$56 \mathrm{~W}$, also see Table 1$)$. The average $( \pm \mathrm{SD})$ absolute difference between the stability ball (B) and chair (C) for time to exhaustion was $25 \pm 22$ seconds.

Table 1. Participant Characteristics

\begin{tabular}{|c|c|c|c|c|}
\hline & $\mathrm{n}$ & Age & $\begin{array}{c}\text { Body Mass } \\
(\mathrm{kg})\end{array}$ & Peak Power (W) \\
\hline Females & 9 & $21 \pm 2$ & $65.9 \pm 9.0$ & $185 \pm 38$ \\
\hline Males & 9 & $26 \pm 7$ & $86.6 \pm 13.5$ & $245 \pm 56$ \\
\hline
\end{tabular}

$($ Mean \pm SD)

ANOVA revealed significant main effects (sitting mode $P=0.003$ and power output, $P<0.001)$ but not interactions $(P>0.390)$ for $\mathrm{VO}_{2}(\mathrm{~mL} / \mathrm{min})$. There were no significant $(P=0.421)$ sex differences for $\mathrm{VO}_{2}$ when body mass was used as a covariate. Paired $t$ tests demonstrated that only peak $\mathrm{VO}_{2}$ (combined female and male data) was significantly $(P=0.001)$ higher by $6 \%$ on $\mathrm{B}$ compared to $\mathrm{C}$. The other stages were $3 \%$ to $6 \%$ higher on $\mathrm{B}$ but not significantly $(P>0.044)$. Average peak $\mathrm{VO}_{2}$ was $38.6+$ $4.1 \mathrm{~mL}^{-1} \mathrm{~kg}^{-1} \mathrm{~min}^{-1}$ on the stability ball and $36.7+5.3$ $\mathrm{mL} \cdot \mathrm{kg}^{-1} \cdot \min ^{-1}$ on the chair. Table 2 reports the $\mathrm{VO}_{2}$ outcomes.

Table 2. $\mathrm{VO}_{2}$ by Sitting Mode \& Sex

\begin{tabular}{|c|c|c|c|c|}
\hline & \multicolumn{4}{|c|}{$\mathrm{VO}_{2}\left(\mathrm{~mL} \cdot \mathrm{min}^{-1}\right)$} \\
\hline & \multicolumn{2}{|c|}{ Female } & \multicolumn{2}{c|}{ Male } \\
\hline & Ball & Chair & Ball & Chair \\
\hline $60 \mathrm{~W}$ & $1029 \pm 80$ & $927 \pm 148$ & $1257 \pm 106$ & $1210 \pm 140$ \\
\hline $\begin{array}{c}50 \% \\
\text { peak }\end{array}$ & $1474 \pm 201$ & $1338 \pm 168$ & $1863 \pm 438$ & $1853 \pm 402$ \\
\hline Penult & $2186 \pm 427$ & $2138 \pm 378$ & $3014 \pm 669$ & $2931 \pm 786$ \\
\hline Peak & $2498 \pm 464$ & $2351 \pm 474$ & $3398 \pm 646$ & $3254 \pm 647$ \\
\hline
\end{tabular}

$($ Mean $\pm \mathrm{SD})$

Heart rate had non-significant sex effect $(P=0.086)$, sitting mode effect $(P=0.291)$ and interactions $(P>0.371)$ but a significant $(P<0.001)$ power output effect. Table 3a reports the HR results and Table $3 b$ reports HR as percentage of peak heart rate.

Table 3a. Sitting Mode Exercise Heart Rates

\begin{tabular}{|c|c|c|c|c|}
\hline & \multicolumn{4}{|c|}{$\operatorname{HR}\left(\mathrm{min}^{-1}\right)$} \\
\hline & \multicolumn{2}{|c|}{ Female } & \multicolumn{2}{c|}{ Male } \\
\hline & Ball & Chair & Ball & Chair \\
\hline $60 \mathrm{~W}$ & $121 \pm 13$ & $121 \pm 10$ & $113 \pm 13$ & $116 \pm 11$ \\
\hline $50 \%$ peak & $146 \pm 13$ & $144 \pm 13$ & $132 \pm 11$ & $139 \pm 9$ \\
\hline Penult & $177 \pm 10$ & $178 \pm 11$ & $170 \pm 11$ & $171 \pm 8$ \\
\hline Peak & $187 \pm 8$ & $188 \pm 9$ & $182 \pm 10$ & $180 \pm 8$ \\
\hline
\end{tabular}

$(\mathrm{Mean}+\mathrm{SD})$ 
Table 3b. Sitting Mode Exercise \% Peak Heart Rate

\begin{tabular}{|c|c|c|c|c|}
\hline & \multicolumn{3}{|c|}{ HR as Percentage of Peak } \\
\hline & \multicolumn{2}{|c|}{ Female } & \multicolumn{2}{c|}{ Male } \\
\hline & Ball & Chair & Ball & Chair \\
\hline $60 \mathrm{~W}$ & $64.5 \pm 6.2$ & $64.5 \pm 4.6$ & $62.2 \pm 6.9$ & $64.6 \pm 6.3$ \\
\hline $50 \%$ peak & $77.8 \pm 5.8$ & $76.7 \pm 4.6$ & $72.7 \pm 5.6$ & $77.0 \pm 4.1$ \\
\hline Penult & $94.2 \pm 2.5$ & $94.5 \pm 2.1$ & $93.4 \pm 2.2$ & $95.0 \pm 2.0$ \\
\hline
\end{tabular}

$($ Mean \pm SD)

Table 4. Sitting Mode Impact on Blood Pressure during Arm Ergometry

\begin{tabular}{|c|c|c|c|c|}
\hline & \multicolumn{2}{|c|}{ SBP $(\mathrm{mmHg})$} & \multicolumn{2}{c|}{ DBP $(\mathrm{mmHg})$} \\
\hline & Ball & Chair & Ball & Chair \\
\hline $60 \mathrm{~W}$ & $128 \pm 13$ & $134 \pm 19$ & $72 \pm 9$ & $70 \pm 9$ \\
\hline $90 \mathrm{~W}$ & $141 \pm 15$ & $149 \pm 24$ & $72 \pm 9$ & $68 \pm 8$ \\
\hline $50 \%$ peak & $152 \pm 19$ & $157 \pm 20$ & $72 \pm 11$ & $70 \pm 8$ \\
\hline
\end{tabular}

$($ Mean $\pm \mathrm{SD})$ For some the $60 \mathrm{~W}$ or $90 \mathrm{~W}$ was also their $50 \%$ peak.

Table 4 contains the blood pressure results. Systolic Blood Pressure (SBP) was significantly $(P=0.043) 4 \%$ to $6 \%$ lower on $\mathrm{B}$ compared to $\mathrm{C}$. Though females tended to be about $10 \mathrm{mmHg}$ lower than males for SBP it was non-significant $(P=0.119)$. There were no significant $(P=$ 0.092) differences between $B$ and $C$ for Diastolic Blood Pressure (DBP). Though females tended to be about 8 $\mathrm{mmHg}$ lower than males for DBP it was non-significantly $(P=0.051)$.

Participants thought one or more muscle groups were affected by the sitting modes: $57 \%$ felt the arm muscles were more active on $B$ than $C$ ( $14 \%$ felt it was higher on C), $50 \%$ felt their gluteal muscles were more active on B $(14 \%$ had more gluteal discomfort on C), and $36 \%$ thought $\mathrm{C}$ had higher thigh activity (with $29 \%$ on B). Figure 1 reports the mean EMG results with paired t test outcomes. ANOVA found significant $(P<0.036)$ sitting mode effect for only the flexor digitorum, quadriceps, and gastrocnemius. Power output main effects were non-significant $(P>0.084)$ for the hamstrings and gastrocnemius but significant $(P<$ 0.005 ) for all other muscle groups. Interaction was significant $(P<0.043)$ for the gastrocnemius and quadriceps while all other interactions were non-significant $(P>0.117)$.

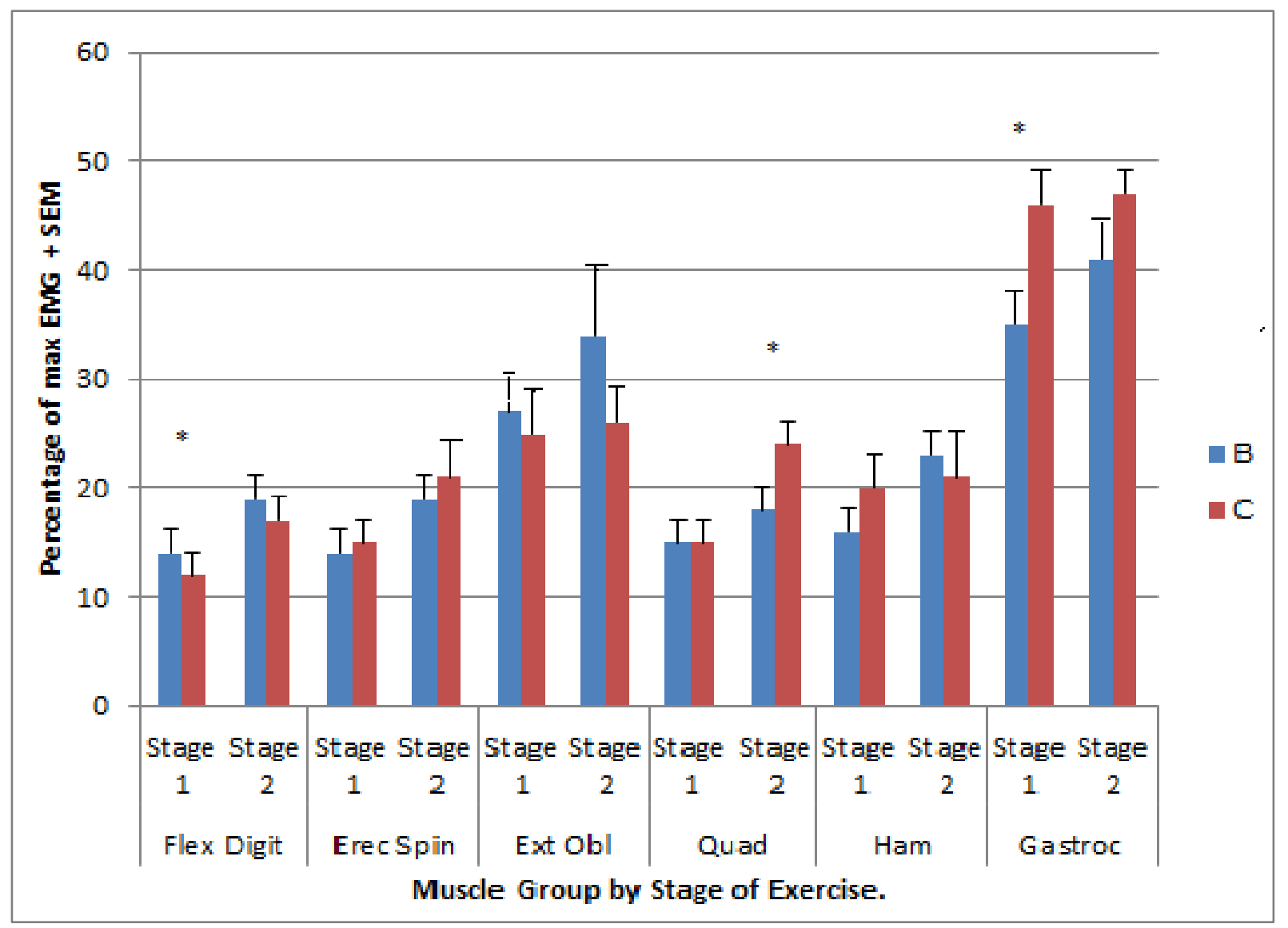

Right side: Flex Digit- Flexor Digitorum, Erec Spin- Erector Spinae, Ext Obl- External Oblique, Quad- Quadriceps, Ham-Hamstrings, GastrocGastrocnemius. ${ }^{*} P<0.012$ between $\mathrm{B}$ and $\mathrm{C}$.

Figure 1. Stability Ball - Chair EMG Differences 
A set of five participant's video files were accidently lost leaving only 13 participants to be analyzed. Hip lateral (HL) and vertical (HV) displacements for B were greater than C. $\mathrm{HL}$ and $\mathrm{HV}$ displacement ANOVAs had significant sitting mode $(P<0.001$ for both) and power output $(P<0.001$ and $P=0.031$, respectively) main effects; however, HL displacement had non-significant $(P=0.558)$ interaction while $\mathrm{HV}$ displacement had significant $(P=0.004)$ interaction. B was significantly $3.5 \pm 2.0 \mathrm{~cm}(P<0.001)$ and $3.3 \pm 2.4 \mathrm{~cm}(P<0.001)$ greater for $\mathrm{HL}$ displacement than $\mathrm{C}$ for stage 1 and 2 of exercise, respectively. In addition, $\mathrm{B}$ had $2.6 \pm 1.8 \mathrm{~cm}$ significantly $(P<.001)$ greater HV displacement than $\mathrm{C}$ for stage 2; however, $\mathrm{B}$ was non-significantly $(P=0.099) 0.7 \pm 1.7 \mathrm{~cm}$ higher than $C$ for stage 1. Figures 2 and 3 report the hip angle and knee angle video analysis of stage 2 while sitting on B and C. There were no significant sitting mode effects or interactions for the hip angle $(P=0.053, P=0.141$, respectively) and knee angle $(P=0.932, P=0.163$, respectively) but significant crank position effects for the hip angle and knee angle (both $P<0.001$ ). The shift from the normal cycling upright sitting position to the semi-recumbent position was $57.9 \pm 1.7^{\circ}$ for $\mathrm{C}$ and $59.5 \pm$ $1.9^{\circ}$ for B. In addition, average sitting heights from a horizontal line through the crank axil were $17.1 \pm 1.5 \mathrm{~cm}$ for $\mathrm{C}$ and $17.8 \pm 2.7 \mathrm{~cm}$ for $\mathrm{B}$.

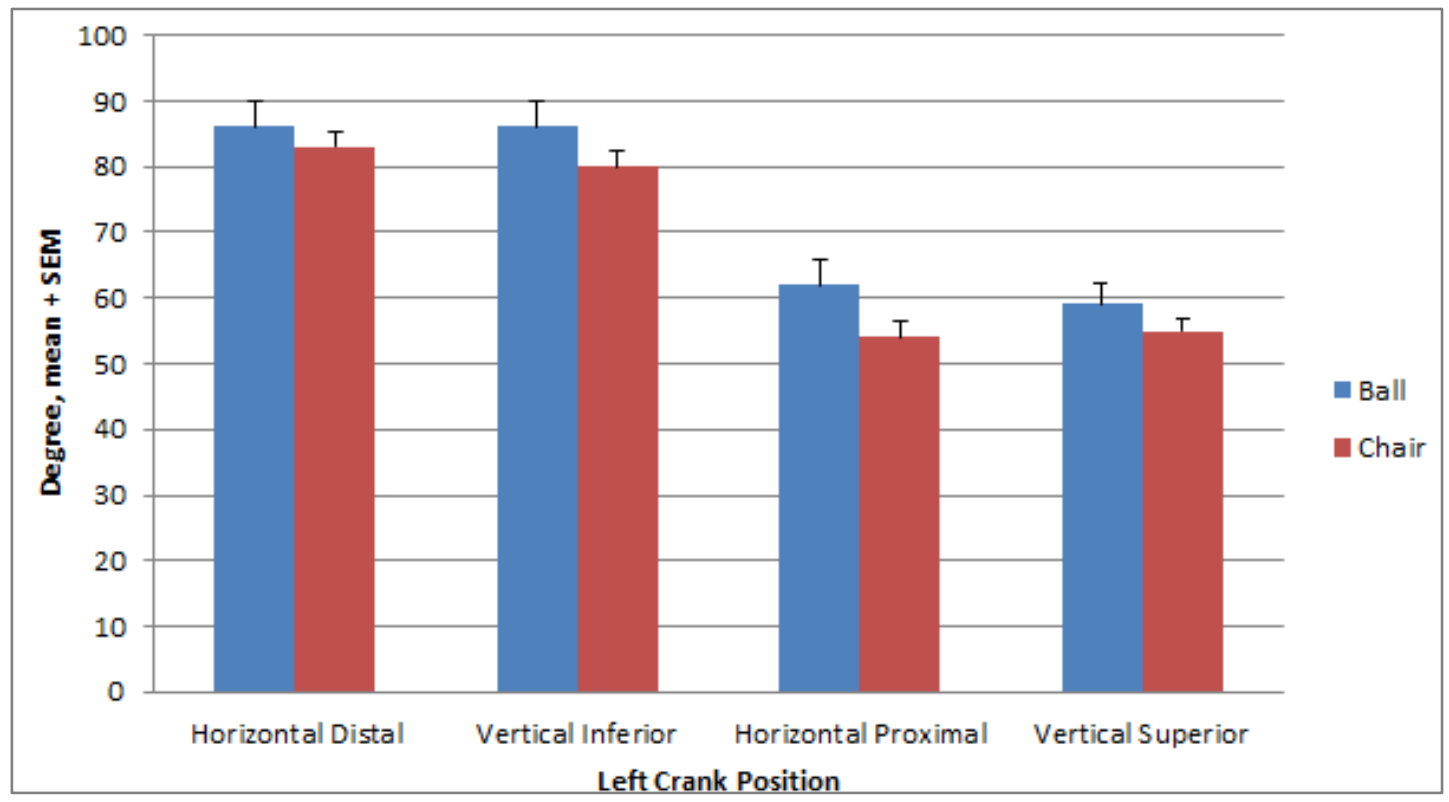

Figure 2. Left Hip Angle during Semi-recumbent Exercise

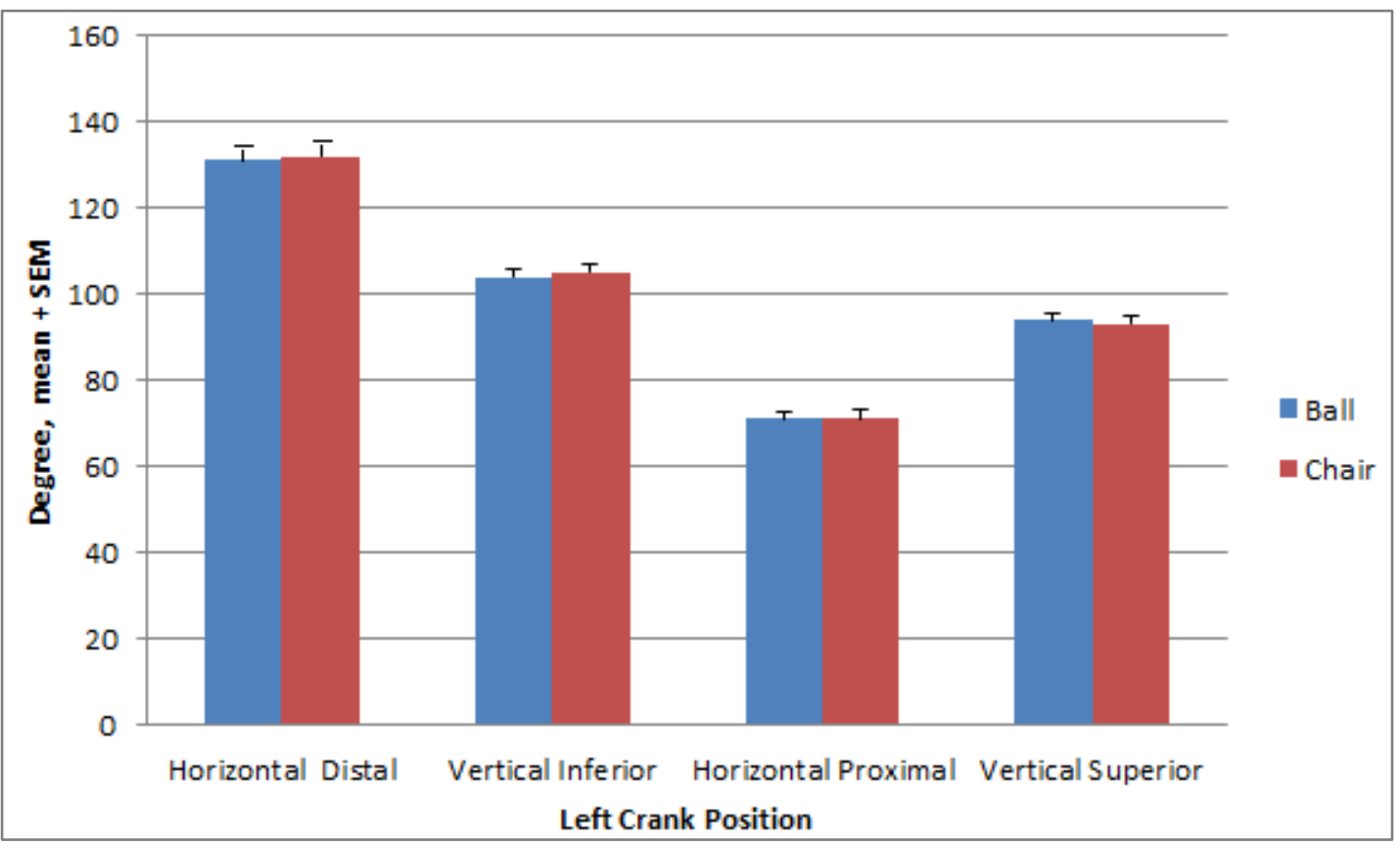

Figure 3. Left Knee Angle during Semi-recumbent Exercise 


\section{Discussion}

This study demonstrated that one can accomplish semi-recumbent exercise without purchasing equipment specifically designed for this type of activity by simply placing a chair or stability ball behind a standard cycle ergometer, placing one's feet into the cycle pedals while sitting on the chair or stability ball, and grabbing the cycle seat with one's hands. One limitation of this setup was that the heels of large shoes could hit the back floor cross support of the cycle, thus the need to remove it. Another was that at high resistances the cycle could move and the reason we placed weights on the front floor cross supports and suction cups on the bracket that held the back floor cross support. This study was also the first study to investigate cardiorespiratory \& muscular responses during aerobic leg exercise while sitting on a stability ball. Because the cycle ergometer in this study was set up in such a way that the participant's arms were used to control their position (by griping onto the cycle seat) the flexor digitorum EMG levels increased with power output for both $\mathrm{B}$ and $\mathrm{C}$. With the added instability of $\mathrm{B}$, the arms were probably working harder to control the body's position as indicated by the higher EMG levels in B when compared to $\mathrm{C}$. This was also supported by the subjective feeling by most participants that their arm muscles were working harder on $\mathrm{B}$. With the increased arm activity and hip displacement on $\mathrm{B}$ one might expect a higher $\mathrm{VO}_{2}$, however, $\mathrm{B}$ resulted only in moderately higher $\mathrm{VO}_{2} \mathrm{~S}$ across all four stages and was significant just at peak. The small differences between $\mathrm{B}$ and $\mathrm{C}$ for $\mathrm{VO}_{2}$ contrasts with the arm ergometry reports where the stability ball had a greater impact on $\mathrm{VO}_{2}[6,7]$. One study [7] indicated that sitting on a stability ball during arm cranking resulted in greater leg muscle activity and this was probably needed to aid in stabilizing the trunk. This greater leg activity probably led to the higher $\mathrm{VO}_{2}$ requirements. The legs in the past study acted as a stabilizer while in the current study the arms acted as the stabilizer. The $\mathrm{VO}_{2}$ differences could be smaller in the current study because of the smaller muscle mass that could be engaged as stabilizers. Also, the typical semi-recumbent machine has a seat with back support and fixed position that provides greater stability and support with little or no need of assistance from the arms. However, in the current study the $\mathrm{C}$ condition had no back support and, therefore, probably required greater control effort (than a standard semi-recumbent machine) by the participants and in turn may have lessened the difference between $\mathrm{B}$ and $\mathrm{C}$ conditions for $\mathrm{VO}_{2}$ and perhaps the trunk EMGs.

Consistent with the earlier arm ergometry studies [6, 7], $B$ did not affect heart rate in the current study. This suggests that the addition of a stability ball would not affect exercise training heart rate prescription in the semi-recumbent position. Since it has been demonstrated that semi-recumbent and upright exercise heart rate prescriptions are similar [12], the current study's result suggest that there is no difference in the heart rate prescription between semi-recumbent exercise on B and upright cycle exercise.

Given the necessity of using both arms to help control the body's position in B and C, especially at the higher intensities, blood pressure measurements were discontinued above $50 \%$ of peak exercise. The current study found that the B condition had a slightly lower SBP and a slightly higher (though non-significant) DBP than C. Using the hands and arms for control during exercise in this study probably resulted in isometric contractions of low intensity at the early stages of exercise. However, at the higher intensities participants used their hands and arms extensively to control their position that may have resulted in heavier isometric contractions. This could be significant since one only need do moderate isometric contractions to elevate blood pressure with single handgrip [15, 16] or isometric for both hands added to moderate dynamic leg exercise [17]. It is reasonable to suppose much higher arm isometric intensities at the higher cycling intensities of the current study and that it could have resulted in much higher blood pressures. Thus caution at this point should be used for certain populations (e.g. hypertensive and cardiac patients) until the blood pressure response at higher intensities of the current study's modality can be clarified.

The lower quadriceps and gastrocnemius activities found on B suggest that the stability ball in the current study might have altered the recruitment pattern of the leg muscles. With more participants reporting their thighs worked harder on $\mathrm{C}$ than those that thought $\mathrm{B}$ was harder supports altered muscle recruitment. In addition, participant comments indicated that half felt greater gluteal effort while on B. These results might indicate greater hip extension accompanied by less knee extension and/or plantar flexion with B. However, though the hips were more extended in all four crank positions on B (Figure 2) none were significant as with the knee extension (Figure 3 ). The loss of data here certainly affected the power of our results. Going from the upright position to the semi-recumbent position and trunk extension can change muscle activation patterns $[18,19,20]$. However, the current study controlled for seat height to be maintain approximately the same between $\mathrm{B}$ and $\mathrm{C}$ and there were no significant hip angle differences. Somatosensory, otolith, and proprioceptive receptors alterations could affect muscle recruitment [4, 21, 22, 23]. Since McGill et al. [5] found that sitting on a stability ball (during resting conditions) had greater contact area between the participant and ball when compared to chair sitting and greater peak contact pressure while sitting on a stool (close to $\mathrm{C}$ in the current study) when compared to sitting on a ball, it is possible that there is a difference in somatosensory activity between $\mathrm{B}$ and $\mathrm{C}$ in the current study. This somatosensory difference may have affected the subjective sense of gluteal activity in some individuals 
in the B condition while giving a possible explanation for the increased discomfort in the $\mathrm{C}$ condition. In addition to the possible differences in contact area and pressure between the $\mathrm{B}$ and $\mathrm{C}$ conditions, the current study had greater vertical and lateral displacement on $\mathrm{B}$. These possible changes in sensory information during the current study might have influenced motor unit recruitment and should be explored further.

The study's conclusions were 1) a stability ball or chair with a cycle ergometer can be used for semi-recumbent exercise with apparently healthy young adults, 2) a stability ball can be a reasonable choice for sitting mode, 3) the $\mathrm{VO}_{2}$ and heart rate results indicated no difference between the stability ball and chair sitting modes for exercise prescription, and 4) the stability ball and chair sitting modes have different leg muscle activities.

\section{Acknowledgements}

The following students assisted with data collection and analysis: Blake Brennan and Jenna Leach.

\section{Conflict of Interests}

No conflict of interests for any of the authors.

\section{REFERENCES}

[1] Duncan M. Muscle activity of the upper and lower rectus abdominis during exercises performed on and off a Swiss ball. J Body Move Ther.2009. 13:364-367.

[2] Marshall PW, Murphy BA. Core Stability Exercise On and Off a Swiss Ball. Arch Phys Med Rehabil. 2005. 86:242-249.

[3] Sternlicht E, Rugg S, Fujii LL, Tomomitsu KF, Seki MM. Electromyographic Comparison of a Stability Ball Crunch With a Traditional Crunch. J Strength Cond Res. 2007. 21(2):506-509.

[4] Gregory DE, Dunk NM, Callaghan JP. Stability Ball Versus Office Chair: Comparison of Muscle Activation and Lumbar Spine Posture During Prolonged Sitting. Human Factors. 2006. 48(1):142-153.

[5] McGill SM, Kavcic NS, Harvey E. Sitting on a chair or an exercise ball: Various perspectives to guide decision making. Clin, Biomech. 2006. 21:353-360.

[6] Marks CRC, Hylland KE, Terrell J. Stability Ball Sitting versus Chair Sitting During Sub-maximal Arm Ergometry. Int J Exerc Sci. 2012. 5(1): 16-25.

[7] Marks CRC, Dupuie L, Patros J. Stability Ball Sitting Elevates Peak Arm ergometry Oxygen Consumption and Heart Rate. Int J Exerc Sci. 2012. 5(4): 360-366.
[8] Franklin BA. Aerobic Exercise Training Programs for the Upper Body. Med Sci Sports Exerc. 1989. 21(5, Suppl): S141-S148.

[9] Keteyian SJ, Marks CRC, Levine AB, Kataoka T, Fedel F, Levine TB. Cardiovascular Responses to Submaximal Arm and Leg Exercise in Cardiac Transplant Patients. Med Sci Sports Exerc.1994. 26(4):420-424.

[10] Eagan M, Columb D, O'Donnell S. Effect of Low Recumbent Angle on Cycling Performance, Fatigue, and $\mathrm{VO}_{2}$ Kinetics. Med Sci Sports Exerc. 2013. 45(5): 663-673.

[11] Scott A, Antonishen K, Johnston C, Pearce T, Ryan M, Sheel AW, McKenzie DC. Effect of Semi-recumbent and Upright Body Position on Maximal and submaximal Exercise Testing. Measure Phys Ed Exerc Sci. 2006. 10(1): 41-50.

[12] Bonzheim SC, Franklin BA, DeWitt C, Marks C, Goslin B, Jarski R, Dann S. Physiologic Responses to Recumbent Versus Upright Cycle Ergometry, and Implications for Exercise Prescription in Patients with Coronary Artery Disease. Am J Cardiol. 1992. 69: 40-44.

[13] Walsh-Riddle M, Blumenthal JA. Cardiovascular responses during upright and semi-recumbent cycle ergometry testing. Med Sci Sports Exerc. 1989. 21(5): 581-585.

[14] Green SB, Salkind NJ. Using SPSS for Windows and Macintosh: analyzing and Understanding Data. $3^{\text {rd }}$ ed. Upper Saddle River (NJ): Prentice Hall; 2003. 231 p.

[15] Kanaley JA, Goulopoulou S, Franklin R, Baynard T, Carhart J. RL, Weinstock RS, Fernhall B. Exercise training improves hemodynamic recovery to isometric exercise in obese men with type 2 diabetes but not in obese women. Metabolism. 2012. 61(12): 1739-1746.

[16] Von Knobelsdorff-Brenkenhoff F, Dieringer MA, Fuchs K, Hezel F, Niendorf T, Schulz-Menger J. Isometric handgrip exercise during cardiovascular magnetic resonance imaging: set-up and cardiovascular effects. J Magn Imaging. 2013. 37(6): 1342-1350.

[17] Strang S. Cardiovascular control during concomitant dynamic leg exercise and static arm exercise in humans. J Physiol. 1999. 514(1):282-291.

[18] Chapman AR, Vicenzino B, Blanch P, Knox JJ, Dowlan S, Hodges PW. The influence of body position on leg kinematics and muscle recruitment during cycling. J Sci Med Sport. 2008. 11: 519-526.

[19] Hakansson NA, Hull ML. Functional Roles of the Leg Muscles When Pedaling in the recumbent Versus the Upright Position. J Biomech Eng. 2005. 127: 301-310.

[20] Savelberg HHCM, Van de Port IGL, Willems PJB. Body Configuration in Cycling Affects Muscle recruitment and Movement Patterns. J Appl Biomech. 2003. 19:310-324.

[21] Amann, M, Proctor LT, Sebranek JJ, Eldridge MW, Pegelow DF, Dempsey JA. Somatosensory Feedback from the Limbs Exerts Inhibatory Influences on Central Neural Drive during Whole Body Endurance Exercise. J Appl Physiol. 2008. 105:1714-1724.

[22] Edgerton VR, McCall GE, Hodgson JA, Gotto J, Goulet C, 
Fleischmann, Roy RR. Sensorimotor adaptations to microgravity in humans. J Exp Bio. 2001. 204: 3217-3224.

[23] Thomas, KE, Bent LR. Subthreshold Vestibular Reflex
Effects in Seated Humans Can Contribute to Soleus Activation When Combined with Cutaneous Inputs. Motor Control. 2013. 17(1):62-74.

* This study was supported in part by an Oakland University Faculty Grant. 